\title{
Early Detection and Monitoring of Cancer Chemotherapy-Related Left Ventricular Dysfunction by Imaging Methods
}

\author{
Mario Luiz Ribeiro, ${ }^{\circledR}$ Antonio José Lagoeiro Jorge, ${ }^{\circledR}$ Marcelo Souto Nacif, ${ }^{\circledR}$ Wolney de Andrade Martins ${ }^{\circledR}$ \\ Universidade Federal Fluminense, Niterói, RJ - Brazil
}

\section{Introduction}

Cancer has been the second leading cause of death in Brazil since 2006, and it is predicted to surpass cardiovascular disease (CVD) as the leading cause of death between 2020 and 2025. ${ }^{1}$ Cancer and CVD have risk factors in common, such as obesity, sedentarism, arterial hypertension, tobacco use, diabetes mellitus, advanced age, and dietary pattern. The co-prevalence of cancer and CVD is therefore elevated. The diagnosis and prevention of both diseases may be carried out in an integrated manner. ${ }^{2}$ Oncological treatment with chemotherapy (CT) has led to an increase in survival, but it has also led to the risk of cardiotoxicity (CTX), the incidence of asymptomatic ventricular dysfunction or even cardiomyopathy. ${ }^{3}$ Early diagnosis of CTX is important, given that the sooner this myocardial event is diagnosed, the higher the chances of recovering systolic function. ${ }^{4}$

The objective of monitoring left ventricular (LV) function during cancer treatment is to detect cardiac dysfunction during the subclinical phase, rather than when a symptomatic patient already has reduced ejection fraction. The groups of chemotherapeutic medications that most frequently cause myocardial aggression are anthracyclines (ANT), widely used in the treatment of solid tumors and hematological malignancies, and monoclonal antibodies, the typical example of which is trastuzumab (TZU). ${ }^{5,6}$ The CTX of ANT was initially described as dose-cumulative, irreversible, and caused by mitochondrial injury. In contrast, TZU-related CTX, which is not dose dependent, is irreversible and does not cause mitochondrial injury. In both aggressions, however, the possibility of reverse remodeling and recovery of ventricular function has been reported. Case series of patients undergoing treatment with ANT reported an incidence of $15 \%$ to $17 \%$ of some degree of decrease in LV ejection fraction (LVEF), calculated by Simpson's method, and $2 \%$ to $3 \%$ of severe heart failure (HF). ${ }^{7}$ More recent case series, however, have related lower incidences.

There are different definitions used for the diagnosis of ventricular dysfunction related to cancer treatment, which are extrapolated from diverse clinical situations and which

\section{Keywords}

Neoplasms/mortality; Antineoplastic Agents/adverse effects; Ventricular Dysfunction, Left/diagnostic imaging; Anthracyclines/adverse effects; Trastuzumab/radiation effects.

Mailing Address: Antonio José Lagoeiro Jorge •

Avenida Marquês do Paraná, 303. Postal Code 24033-900, Centro, Niterói, RJ - Brazil

Email: lagoeiro@cardiol.br, lagoeiro@globo.com

Manuscript received March 05, 2018, revised manuscript November 21, 2018, accepted December 05, 2018

DOI: 10.5935/abc.20190022 have little specific validation. Currently, one of the most used definitions is as a decrease in LVEF of more than $10 \%$ of the baseline value, to values below the cutoff of $53 \%$, with or without symptoms, it being necessary to repeat the exam 2 or 3 weeks after the initial measurement. ${ }^{8}$ According to Zamorano et al. ${ }^{9}$ this lower limit for LVEF normality is $50 \%$, also with a $10 \%$ reduction. Other definitions quantify a decrease in LVEF of more than $10 \%$ to LVEF below $55 \%$, in asymptomatic patients, or a decrease of more than 5\% to LVEF below 55\% in symptomatic patients. ${ }^{10}$ Initially, endomyocardial biopsy was the gold standard used for cardiotoxicity, but its invasive character and risk of complications led to its progressive replacement by imaging methods. Various techniques have been proposed as tools for diagnosis and prognosis of CTX associated with $\mathrm{CT}$, with emphasis on serum biomarkers, conventional echocardiography, two-dimensional strain echocardiography, radionuclide ventriculography (RNV), and cardiac magnetic resonance imaging (CMRI). The objective of this review is to present clinicians with the main advantages and disadvantages of different imaging methods for diagnosing and monitoring chemotherapy-related left ventricular dysfunction, regarding critical analysis, accuracy, limitations, and clinical perspectives.

\section{Methods}

This review followed adaptations of the Preferred Reporting Items for Systematic Reviews and Meta-Analyses (PRISMA) methodology principles. The bibliographic search included the databases MEDLINE, SciELO, and LILACS. The descriptors used were cardiotoxicity; left ventricular dysfunction; antineoplastics; anthracyclines; diagnostic techniques and procedures; echocardiography; Doppler echocardiography; two-dimensional/three-dimensional/ contrast echocardiography; scintigraphy; nuclear medicine; computed tomography; magnetic resonance. The reference lists of the articles found in the electronic search were also consulted and relevant articles were, thus, identified. The objective was to answer the question which is the most appropriate imaging method for the early detection of ventricular dysfunction in patients submitted to cancer CT within the context of clinical practice. Two independent researchers independently analyzed all abstracts. The review considered original articles with the following study designs: clinical trial, cohort, case-control, meta-analysis, and reviews that had expert consensus; considering articles published in the period between January 1998 and June 2017, whose full texts were available in English, Spanish, or Portuguese. The studies were selected in accordance with the following criteria: (a) the underlying disease was cancer, with a diagnosis confirmed by histopathology; (b) treatment included CT with ANT, TZU, or other known myocardial depressants; and 
(c) diagnostic methods such as echocardiography, computed tomography, nuclear medicine, or magnetic resonance imaging were used. The following were excluded: case reports, articles with other types of oncological therapy, and duplicate articles. Two hundred and twenty-one abstracts in the databases fulfilled the search criteria, and 162 articles were excluded.

Hereafter, we will critically analyze each of the methods, highlighting their advantages, disadvantages, and clinical applicability regarding the detection of CT-induced CTX. A summary of this analysis is given in Table 1 .

\section{Two-dimensional echocardiography}

Two-dimensional echocardiography (2D ECHO) with Doppler is the method most frequently used before, during, and after $\mathrm{CT}$, given that it is not invasive; it does not use ionizing radiation; it is highly available and cost-effective. It evaluates systolic and diastolic function, cardiac valves, and the pericardium, thus offering an analysis of diverse manifestations of CTX.11 The quantification of LVEF is the most accepted for measuring LV systolic function, and it is an important parameter in the algorithm for monitoring CT-induced CTX, capable of diagnosis and prognosis of clinical results, supporting the decision to continue or stop antineoplastic therapy. ${ }^{8}$ It is important that this measure be accurate, with minimal temporal variability. However, LVEF measured by $2 \mathrm{D} \mathrm{ECHO}$ has an elevated temporal variability, approximately $10 \%[9,1 \%-11,8 \%]$, and in order to be able to detect a $10 \%$ alteration in LVEF safely, the measure should have a lower temporal variability. It is thus possible to affirm that LVEF measured by $2 \mathrm{D} \mathrm{ECHO}$ is less reliable. ${ }^{12}$

Reduced LVEF following CT is considered a late finding that may indicate irreversible myocardial aggression and impede evolution with adequate therapy. Diastolic dysfunction may precede and predict late systolic dysfunction; however, no parameter of diastolic function has definitively shown to be predictive of CTX, and the studies are conflicting. ${ }^{13-17}$
The right ventricle (RV) is commonly affected by $\mathrm{CT}$, in an early manner, with a higher number of affected segments than the LV, predominantly in the interventricular septum. ${ }^{18}$ Its routine evaluation should follow the recommendations set forth by Lang et al..$^{19}$ In this manner, the quantification of RV systolic and diastolic function would be important for serial monitoring, but there is a significant technical difficulty which restricts its routine use in clinical practice.

In summary, a disadvantage of $2 \mathrm{D} \mathrm{ECHO}$ is the elevated intra- and inter-examiner variability that compromises the method's reproducibility.

\section{Three-dimensional echocardiography}

Unlike 2D ECHO, the evaluation of LVEF volumes by $3 \mathrm{D} \mathrm{ECHO}$ is not based on geometrical suppositions; it is not affected by shortened views, ${ }^{20}$ and it is quantified by an automated edge-tracking algorithm. ${ }^{21}$ Studies with CMRI have shown that evaluations of LVEF and LV volumes by $3 \mathrm{D}$ ECHO have better accuracy and reproducibility, ${ }^{22,23}$ as well as lower temporal variability for serial monitoring of LVEF. ${ }^{12}$

The study by Walker et al. ${ }^{23}$ evaluated the accuracy of measuring LVEF with 2D ECHO, RNV, and 3D ECHO with relation to CMRI, in patients who used Doxorubicin (DOX) and TZU. The left ventricle final diastolic volume (LVFDV) showed a modest correlation between $2 \mathrm{D}$ ECHO and CMRI $(r=0.64$ baseline, $r=0.69$ at 12 months); the correlation of LVFDV between 3D ECHO and CMRI was shown to be stronger ( $r=0.87$ baseline; $r=0.95$ at 12 months); LVEF measured by $2 \mathrm{D} \mathrm{ECHO}$ had a weak correlation with $\mathrm{CMRI}$ $(r=0.31$ baseline, $r=0.42$ at 12 months). Both 3D ECHO and RNV showed a strong correlation when comapred with CMRI ( $r=0.91$ baseline, $r=0.90$ at 12 months). When compared with RNV, the serial measurement of LVEF via 3D ECHO was shown to be more viable, accurate, and reproducible for serial LVEF monitoring in these patients.

Table 1 - Advantages, disadvantages, and applicability of imaging methods for detecting chemotherapy-related cardiotoxicity

\begin{tabular}{|c|c|c|c|}
\hline Method & Advantages & Disadvantages & Applicability \\
\hline 2D ECHO & $\begin{array}{c}\text { • Available } \\
\text {-Allows for serial repetition } \\
\text { - Evaluates anatomy and function }\end{array}$ & $\begin{array}{l}\text { • High variability } \\
\text { - Late detection of alterations }\end{array}$ & $\begin{array}{c}\text { • Screening exam } \\
\cdot \text { Established diagnosis of disease }\end{array}$ \\
\hline $\begin{array}{l}\text { 2D ECHO + } \\
\text { Simpson + } \\
\text { Contrast }\end{array}$ & - Improves accuracy with respect to $2 \mathrm{D} \mathrm{ECHO}$ & $\begin{array}{l}\cdot \text { Higher cost } \\
\text { - Longer exam time }\end{array}$ & $\begin{array}{l}\text { - Allows for accurate evaluation with } \\
\text { simpler, more accessible technology }\end{array}$ \\
\hline 3D ECHO & - Accuracy and reproducibility close to that of CMRI & - Low availability & - Accurate detection \\
\hline 2D STE & - Detects subclinical dysfunction & $\begin{array}{c}\text { - Low availability } \\
\text { - Depends on } \\
\text { echocardiographic window }\end{array}$ & $\begin{array}{l}\text { - Initial screening of patients who will } \\
\text { need monitoring }\end{array}$ \\
\hline RNV & - Excellent accuracy and reproducibility & $\begin{array}{c}\cdot \text { Low availability } \\
\text { - Does not evaluate other structures, } \\
\text { such as valves, pericardium }\end{array}$ & $\begin{array}{c}\text { - In doubts regarding ECHO } \\
\text { measurements of LVEF } \\
\text { •Inadequate ECHO image quality }\end{array}$ \\
\hline CMRI & $\begin{array}{l}\text {-Allows for diagnosis of other etiologies of cardiomyopathy } \\
\qquad \text {-Allows for tissue characterization }\end{array}$ & $\begin{array}{l}\text { - Long exam time } \\
\text { - Cost }\end{array}$ & $\begin{array}{l}\text { - In doubts regarding ECHO } \\
\text { measurements of LVEF }\end{array}$ \\
\hline
\end{tabular}

2DECHO: two-dimensional echocardiography; 3D ECHO: three-dimensional echocardiography; 2D STE: ecocardiograma bidimensional com strain; RNV: radionuclide ventriculography; CMRI: cardiac magnetic resonance imaging; LVEF: left ventricular ejection fraction 


\section{Review Article}

Echocardiography is the method of choice for serial evaluation of patients undergoing CT, considering availability, cost, and risk. Accurate LVEF calculation should be carried out with the best available method in the echocardiography laboratory, ideally 3D ECHO. In the event that 2D ECHO is used, Simpson's is the preferred method. ${ }^{8}$ When utilizing $2 \mathrm{D} \mathrm{ECHO}$, contrast should be associated to improve the accuracy and reproducibility of the measurements of LVEF and volumes. ${ }^{24}$

\section{Myocardial two-dimensional strain echocardiography}

Two-dimensional speckle tracking echocardiography (2D STE) is an accurate technique, which is easy to perform and which has good reproducibility. It measures myocardial deformation through strain and strain rate in the three spatial planes, i.e. longitudinal, circumferential, and radial. Left ventricular systolic global longitudinal strain (LVGLS) has an intra- and inter-observer variability of $4.9 \%$ to $8.6 \%$, which is lower than the that of the measurement of LVEF. ${ }^{25}$ Its prognostic value is incremental to LVEF for the prediction of all-cause mortality in the general population. ${ }^{26}$ Strain and strain rate are attributed to have the capacity to detect subclinical LV dysfunction and cardiac dysfunction related to $\mathrm{CT}$, especially with the use of ANT and TZU.

In the study by Charbonnel et al., ${ }^{27}$ LVGLS measured before treatment and after low doses $\left(150 \mathrm{mg} / \mathrm{m}^{2}\right)$ of ANT was shown to be a predictor of alterations in LVEF 12 months after the initial dose; CTX occurred in 6 of the 86 patients (7.0\%). Pre-CT evaluation of LVGLS was observed to have a predictor value with an area under the ROC curve of 0.76 , with a predictor threshold of (-)19.95\% for LVGLS; in the evaluation with low doses, LVGLS provided incremental predictive information on CTX with an area under the ROC curve of 0.82 , for a predictor threshold of (-)17.45\% for LVGLS.

The study by Mousavi et al. ${ }^{28}$ demonstrated that LVGLS was a strong predictor of symptomatic HF in pre-CT evaluation of patients undergoing CT with ANT. Age and LVGLS were also predictors of all-cause mortality. LVGLS greater than (-)16\% was associated with a 4.7 -fold increase in the occurrence of symptomatic HF.

Our cardio-oncology research group studied pre-CT LVGLS as a predictor of LV dysfunction and found data (yet to be published) similar to those of the above-cited authors. ${ }^{27,28}$

In 52 patients with breast cancer undergoing CT with ANT, who were studied 1 week before CT and after the complete cycle, a significant decrease in LVGLS occurred, which was not accompanied by a decrease of more than $10 \%$ in LVEF, which suggests that LVGLS is more sensitive than LVEF in detecting alterations in systolic function. ${ }^{17}$

In patients with non-Hodgkin's lymphoma, followed for 6 months, there was a significant reduction in LVGLS and an increase in cardiac troponin T (cTnT); LVEF, however, remained within reference values. When alterations in LVGLS and cTnT were included in the multivariate analysis, only the decrease in LVGLS between the baseline and the third cycle of CT was an independent predictor of CTX; there was, however, no long-term follow-up to determine the clinical relevance of these findings in predicting late cardiac events. ${ }^{29}$
Sawaya et al. ${ }^{30}$ followed 43 patients with breast cancer treated with ANT and TZU, performing 2D STE and measuring biomarkers at baseline and at 3 and 6 months. High-sensitivity cardiac troponin I (hsTnl) and LVGLS were early markers of subsequent decreases in LVEF. Patients who presented neither a decrease of more than $10 \%$ in LVGLS nor an elevation in hsTnl during the third month had a $3 \%$ probability of a decreased LVEF in the sixth month. Patients who had a decrease of more than $10 \%$ in LVGLS and/or an elevation in hsTnl presented a risk of CTX during the sixth month 9 times greater than those without either of these alterations. The authors infer that the presence of these markers does not mandate the suspension of $\mathrm{CT}$ but rather alerts that there is a necessity for closer cardiac monitoring, earlier initiation of "cardioprotective" measures, or the use of alternative, less cardiotoxic therapies. ${ }^{30}$

Sawaya et al. ${ }^{31}$ followed 81 patients treated with ANT, taxanes, and TZU, 26 of which developed CTX, 5 with symptoms of HF. LVGLS and hsTnl were predictors of CTX, and LVGLS greater than (-)19\% was present in all of those who developed symptoms of HF.

According to Negishi et al. ${ }^{32}$ a relative reduction in LVGLS of more than $11 \%$, with respect to the pre-CT exam, is the best predictor of CTX. In the absence of a pre-CT exam, LVGLS greater than (-)20,5\% would also be a predictor of CTX, albeit, with a lower area under the ROC curve (0.67); they thus suggest using relative reduction rather than absolute value.

Forty-two patients with ANT and TZU regimes were followed for 12 months, and 10 of them developed CTX. LVGLS, left ventricular systolic global radial strain (GRS), and $\mathrm{S}^{\prime}$ detected a pre-clinical reduction in the third month, and all 10 who developed CTX had a reduction in LVEF at 6 months. ${ }^{33}$

Even though there is a consensus regarding the need for cardiac function monitoring via non-invasive imaging after exposure to $\mathrm{CT}$, the method to be utilized and the monitoring time have yet to be defined. Evidence suggests that a reduction in LVGLS precedes a decrease in LVEF; however, long-term follow-up is necessary to determine the clinical relevance of these findings.

\section{Radionuclide ventriculography}

RNV was the first scintigraphic method for serial evaluation of LVEF in patients undergoing CT. ${ }^{34,35}$ Its advantages include excellent accuracy, an estimated intra- and inter-variability of less than 5\%, independence from LV geometry, and the possibility of being performed in patients with large body surfaces. ${ }^{36,37}$ Gated single-photon emission computed tomography (SPECT) has currently been used to measure LVEF; nevertheless, the American Society of Nuclear Cardiology recommends that serial monitoring be performed by RNV as a Class I indication, whereas the gated blood-pool SPECT technique is a Class IIb indication. ${ }^{36}$ Limitations to the routine use of nuclear imaging include patients with arrhythmias; incompleteness of information on the right ventricle, the atria, the valves, and the pericardium; repeated exposure to ionizing radiation; and higher costs compared to echocardiography. In 2016, the American Society of Clinical Oncology published guidelines on the prevention and monitoring of cardiac 
dysfunction in adult cancer patients, recommending the use of $\mathrm{RNV}$ or CMRI in cases where echocardiography is not available or technically feasible, for example, in cases with inadequate ultrasound windows. ${ }^{38}$ In addition to evaluating systolic function, RNV has demonstrated value in following diastolic function in patients exposed to cardiotoxic medications.

\section{Radionuclide ventriculography versus echocardiography}

RNV was more sensitive than echocardiography in detecting early decreases in LVEF. ${ }^{39,40}$ However, in these small studies, there was a high incidence of CTX (over 48\%) without long-term follow-up. This limitation did not allow for correlations to be drawn with HF incidence. In a study of breast cancer patients who received ANT and TZU, measurements of LVEF by 3D ECHO and RNV were comparable, with CMRI used as a reference. ${ }^{23} \mathrm{~A}$ document titled "American Society of Echocardiography Expert Consensus Statement for Multimodality Imaging Evaluation of Adult Patients During and After Cancer Therapy" ${ }^{\prime 8}$ recommends the use of 2D ECHO or 3D ECHO for evaluating LVEF before, during, and after CT. In the case of inadequate image quality, the use of CMRI is recommended; RNV is not mentioned as a routine method. The specific availability of each service certainly interferes with the choice of method. There are currently new scintigraphic methods with other markers of early myocardial injury, ${ }^{35}$ which are capable of subclinically detecting LV dysfunction and which could predict the development of subsequent LV dysfunction or HF, such as sympathetic neural imaging with the ${ }^{123} \mathrm{I}$-meta-iodobenzylguanidine $\left({ }^{123} \mathrm{I}-\mathrm{mIBG}\right)$ technique, imaging of cell death ( ${ }^{111}$ In-antimiosina), targeted therapy imaging ( $\left.{ }^{111} \mathrm{In}-\mathrm{TZU}\right)$, and molecular metabolic imaging of PET. All of these techniques have yet to be clinically validated for use in this CTX situation.

Studies with the adrenergic marker of neuronal integrity ${ }^{123}$ I-mIBG carried out in patients using ANT demonstrated that scintigraphy with $\mathrm{mIBG}$ is capable of identifying patients with a higher risk of CTX with great accuracy. ${ }^{41}$

\section{Cardiac magnetic resonance imaging}

\section{Functional evaluation (cine MR and tagging/strain)}

CMRI is the gold standard evaluation of LVEF volumes, using the technique of cine MR with quantification by Simpson's method. Its routine utilization is limited by availability and cost. $^{42,43}$ In addition to accurately evaluating left and right ventricular function, CMRI can identify other probable causes associated with cardiomyopathy, such as myocardial invasion of the tumor, amyloidosis, sarcoidosis, myocarditis, and atherosclerotic coronary disease. CMRI should always be considered the first step before endomyocardial biopsy. ${ }^{8}$

Draft et al. ${ }^{44}$ detected subclinical abnormalities in geometry and ventricular function, such as a significant increase in final systolic volume, decreased LVEF and increased average circumferential strain in patients receiving low to moderate doses of anthracyclines. These markers are not usual criteria for CTX and the relation with prediction of future events is unknown. Armstrong et al. ${ }^{45}$ also detected subclinical cardiac dysfuntion using CMRI, analyzing LVEF and LV volume.
No study of CMRI to date has demonstrated that alterations in myocardial function indexes after CT with ANT were predictors of subsequent CTX or HF. An ongoing observational study is assessing whether LV function measured by CMRI in patients using ANT, with or without TZU, will be able to predict a decrease in LVEF in 24 months. ${ }^{46}$

According to Plana et al., ${ }^{8} \mathrm{CMRI}$ should be used to confirm alterations in LVEF reported by other techniques or when there is a conflict between measurements from different techniques. This is only justified in the event that there is a plan to modify or interrupt CT. It is of little interest to use CMRI for diastolic function analysis due to the fact that its accuracy is similar to that of echocardiography. ${ }^{47,48}$

There are few studies on the evaluation of myocardial strain by CMRI for evaluating CT-related CTX. In the trial by Draft et al., ${ }^{44}$ there was an early increase in midwall circumferential strain, after a month of therapy with ANT, associated with subclinical abnormality in ventricular function, demonstrated by a decrease in LVEF evaluated by CMRI. It is necessary to determine if these markers are associated with cardiovascular events in survivors of cancer.

Tissue characterization (myocardial enhancement/T1 mapping/T2 mapping)

Myocardial tissue characterization of CTX dates back to the 1980s, when necropsy and biopsy studies revealed that myocardial inflammation and cardiomyocyte edema are early findings of CTX, which occur prior to reduced myocardial function, as opposed to myocardial fibrosis, which is a late finding. ${ }^{49,50}$ In addition to its functional evaluation, CMRI is capable of performing morphological and tissue evaluation in a qualitative (visual) and quantitative manner, as percentage of muscle affected. ${ }^{51}$ Myocardial interstitial injuries may or may not be reversible, depending on different factors which include the degree of interstitial fibrosis. In this manner, CMRI is able to establish the differential diagnosis between reactive, infiltrative, and scar fibrosis. ${ }^{52}$

It is possible to evaluate CTX on the tissue level with early and late enhancement techniques. ${ }^{52}$ The main disadvantage is that, in the large majority of subclinical disease cases, there is no visually detectable fibrosis to be quantified and this technique is negative.

T1 mapping has been validated for detection of interstitial fibrosis not detected by late enhancement techniques, and the results are informed through the quantification of myocardial relaxation time in milliseconds. ${ }^{53}$ During postcontrast, the lower the myocardial T1, the higher the degree of interstitial fibrosis. T1 mapping has shown to be an independent predictor of CTX in patients treated with ANT who were followed for a period of 3 years. ${ }^{54}$ Extracellular volume (ECV) fraction which indicates the expansion of interstitial space corrected by hematocrit was also a strong imaging biomarker. ${ }^{54}$

T2 mapping is responsible for the quantification of cardiomyocyte edema, and it assists in the characterization of acute, subacute, or chronic damage. ${ }^{55}$ The results of T2 mapping are also represented by time in milliseconds. A study with 9 patients who received ANT showed that average T2 values $>59 \mathrm{~ms}$ were associated with CTX. ${ }^{56}$ 


\section{Review Article}

Myocardial tissue characterization by CMRI may detect early myocardial injury during CT and identify subclinical myocardial alterations in cancer survivors; however, prospective studies are needed to confirm this hypothesis. The cost-effectiveness of using CMRI in comparison with other sequential follow-up techniques for patients undergoing CT still needs to be quantified.

\section{Cardiac computed tomography (coronary angiotomography)}

Coronary angiotomography is a method with growing clinical applicability that uses low doses of radiation (1-2 mSv) and iodinated contrast $(50 \mathrm{~mL}) .^{57}$ In addition to its classical indications, it is possible to quantify the volumes and ejection fractions of both ventricles. ${ }^{58}$ After the study by Nacif et al., ${ }^{59}$ the use of angiotomography for the quantification of myocardial interstitial fibrosis via the quantification of VEC may be of great clinical utility. VEC values greater than 35\% are associated with interstitial fibrosis.

\section{Rational approach strategy for early detection of CTX}

In Figure 1, we propose a flowchart showing the rational approach for patients undergoing CT. This algorithm is based on a review of the literature and the authors' expertise. It thus lacks validation in randomized controlled clinical trials. This approach should be adapted to the reality of each service's supply and demand conditions. ${ }^{8}$ Faced with a cancer patient, the following steps are recommended: (a) integrated actions, shared by cardiologists and oncologists, within a multidisciplinary team; (b) clinical evaluation of estimated global cardiovascular risk, previous diseases, previous chemo- or radiotherapy and, when indicated, specific intervention prior to CT; (c) within the institution's limitations, consider two-dimensional echocardiography with measurements of strain. (d) In the event that baseline cardiac evaluation is not available for all patients, prioritize those with high risks of CTX, such as those with CVD or cardiovascular risk factors; LV systolic dysfunction; over 65 years of age; a regimen with doses of ANT (DOX) greater than $350 \mathrm{mg} / \mathrm{m}^{2}$; or combination CT (Figure 1).

If one the following is detected in a patient being monitored: LVEF < 53\%, LVGLS below the lower limit of normality, or elevated troponins, in the absence of symptoms, the cardiologist should be consulted and the risk-benefit ratio related of CT discussed with the oncologist. Whether to continue or not is, however, the oncologist's decision. The healthcare flowcharts depend on the cardiotoxic potential of the $\mathrm{CT}$ regimen. In accordance with documents by the American and European societies of echocardiography, patients with cumulative doses below $240 \mathrm{mg} / \mathrm{m}^{2}$ of DOX should repeat the cardiac evaluation at the conclusion of the CT regimen and 6 months later. ${ }^{8}$ In patients with doses above $240 \mathrm{mg} / \mathrm{m}^{2}$ there should be a new evaluation before each additional $50 \mathrm{mg} / \mathrm{m}^{2}$ cycle. In patients receiving TZU, there should, ideally, be an echocardiogram every 3 months. ${ }^{8}$ Owing to the unavailability of data, in patients undergoing therapy with vascular endothelial growth factor inhibitors, evaluation with echocardiography 1 month after the initial dose and, subsequently, every 3 months, is recommended. ${ }^{8}$

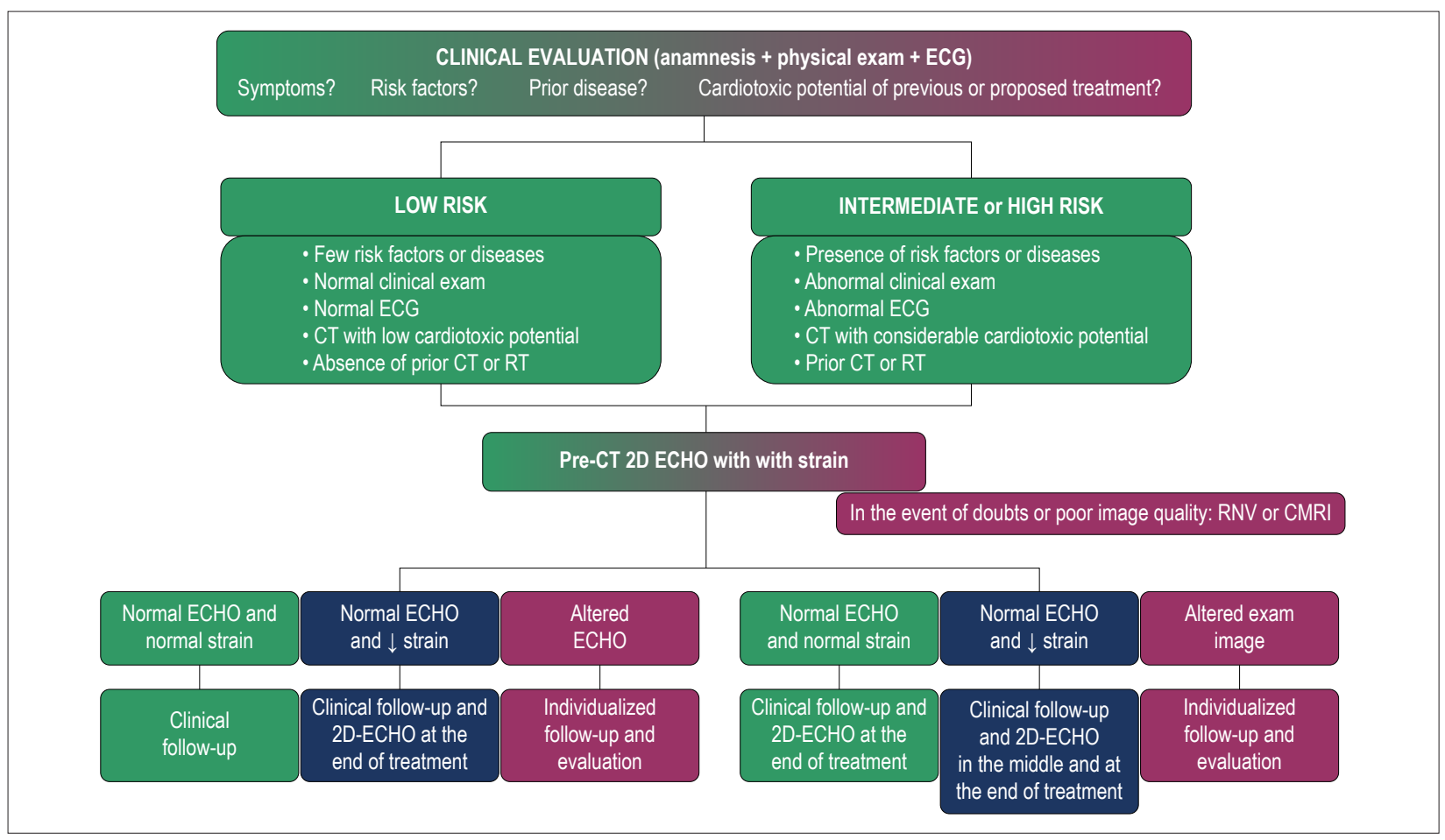

Figure 1 - Proposal for cardiovascular monitoring of patients undergoing chemotherapy based on information in the literature and authors' expertise. ECG: electrocardiogram; CT: chemotherapy; RT: radiation therapy; 2D-ECHO: two-dimensional echocardiography; RNV: radionuclide ventriculography; CMRI: cardiac magnetic resonance imaging; ECHO: echocardiography. 
Subclinical detection of left ventricular dysfunction

To date, there is no evidence regarding the treatment of asymptomatic patients with preserved LVEF and alterations exclusively in strain. However, the rationale for measuring strain is based on the possibility of frequently monitoring patients at risk and, as soon as a decrease in LVEF is detected, initiating therapy and obtaining reverse remodeling.

For the purpose of detecting subclinical dysfunction, baseline LVGLS is the marker for comparison of post-CT measurements. A relative reduction of more than $15 \%$ can confirm the dysfunction. This altered value should be confirmed by a new exam 2 or 3 weeks later. Elevated Tnl with or without alterations in LVGLS is also considered a marker of myocardial injury; there are, however, multiple causes of elevations in Tnl, as well as doubts regarding its prognostic value for ventricular dysfunction. Whenever the need for suspending $\mathrm{CT}$ is considered in asymptomatic patients, it is necessary to measure LVEF using a more accurate method, such as RNV or CMRI.

There are no studies with safe levels of evidence demonstrating the benefits of pharmacological "cardioprotective" treatment in patients undergoing CT. When considering the hypothesis of continuing CT notwithstanding alternations in LV function, echocardiographic re-evaluation is necessary before the new cycle, with the awareness that the risk of CTX will progressively increase.

Additional imaging exams are not necessary for patients who have concomitant risk factors, in the presence of normal GLS or troponins during CT and 6 months after the last CT with ANT. Following completion of the therapeutic regimen, there should be annual clinical cardiovascular examination and the use of cardiac imaging in accordance with the services available. ${ }^{8}$

\section{Conclusions}

Monitoring LVEF by $2 \mathrm{D}$ ECHO is the most executable strategy for detecting CT-related cardiovascular disease in large groups of patients; this method should, however, be considered in the context of its numerous limitations.
$3 \mathrm{D} \mathrm{ECHO}$ is the method of choice when considering accuracy together with availability, limitations regarding repetition, and ease of execution. When this is not available, the addition of contrast to 2D ECHO should be encouraged, seeing that this increases accuracy. LVGLS is the best parameter of myocardial deformation for subclinical detection of LV dysfunction; however, there is no solid evidence showing the benefits of initiating early "cardioprotective" therapy based on its results. RNV has a high diagnostic accuracy for ventricular dysfunction and may be an alternative in the event of doubts regarding echocardiography. CMRI assists in differential diagnoses with other causes of cardiomyopathies.

The decision to interrupt or continue a chemotherapeutic regimen is clinical, joint, and multidisciplinary, and it is based on the risk-benefit ratio for each patient.

Randomized controlled clinical trials with long-term follow-up are necessary to determine whether early detection of cardiac dysfunction is a predictor of LVEF reduction and, above all, HF and major cardiovascular events.

\section{Author contributions}

Conception and design of the research: Ribeiro ML, Martins WA; acquisition of data and analysis and interpretation of the data: Ribeiro ML; writing of the manuscript and critical revision of the manuscript for intellectual content: Jorge AJL, Ribeiro ML, Nacif MS, Martins WA.

\section{Potential Conflict of Interest}

No potential conflict of interest relevant to this article was reported.

\section{Sources of Funding}

There were no external funding sources for this study.

\section{Study Association}

This article is part of the thesis of Doctoral submitted by Mário Luiz Ribeiro, from Universidade Federal Fluminense. 


\section{Review Article}

\section{References}

1. Brasil. Ministério da Saúde. Dados de Taxa de Mortalidade Específica (TME). DATASUS 2008/2009 disponível em http://tabnet.datasus.gov.br/cgi/tabcgi. exe?idb2009/c10.def. Acesso em 20/01/2011

2. Martins WA, Moço ETSM. Cardio-oncologia: o preço do envelhecimento. Rev Bras Cardiol.2012;25(3):164-6.

3. Yeh ET, Tong AT, Lenihan DJ, Yusuf SW, Swafford J, Champion C, et al. Cardiovascular complications of cancer therapy: diagnosis, pathogenesis, and management. Circulation.2004;109(25):3122-31.

4. Cardinale D, Colombo A, Torrisi R, Sandri MT, Civelli M, Salvatici M, et al. Trastuzumab-induced cardiotoxicity: Clinical and prognostic implications of troponin I evaluation. J Clin Oncol.2010;28(25):3910-6.

5. Doyle JJ, Neugut AI, Jacobson JS, Grann VR, Hershman DL. Chemotherapy and cardiotoxicity in older breast cancer patients: a population-based study. J Clin Oncol.2005; 23:8597-605.

6. Armstrong GT, Oeffinger KC, Chen Y, Kawashima T, Yasui Y, Leisenring W, et al. Modifiable risk factors and major cardiac events among adult survivors of childhood cancer. J Clin Oncol.2013;31(29):3673-80.

7. Mackey JR, Martin M, Pienkowski T, Rolski J, Guastalla JP, Sami A, et al. Adjuvant docetaxel, doxorubicin, and cyclophosphamide in node-positive breast cancer: 10-year follow-up of the phase 3 randomised BCIRG 001 trial. Lancet Oncol.2013;14:72-80.

8. Plana JC, Galderisi M, Barac A, Ewer MS, Ky B, Scherrer-Crosbie M, et al. Expert consensus for multimodality imaging evaluation of adult patients during and after cancer therapy: A report from the American Society of Echocardiography and the European Association of Cardiovascular Imaging. J Am Soc Echocardiogr.2014;27(9):911-39.

9. Zamorano JL, Lancellotti P, Munoz DR, Aboyans V, Asteggiano R, Galderisi M, et al. 2016 ESC Position Paper on cancer treatments and cardiovascular toxicity developed under the auspices of the ESC Committee for Practice Guidelines: The Task Force for cancer treatments and cardiovascular toxicity of the European Society of Cardiology (ESC). Eur J Heart Fail.2017;19:9-42.

10. Seidman A, Hudis C, Pierri MK, Shak S, Paton V, Ashby M, et al. Cardiac Dysfunction in the Trastuzumab Clinical Trials Experience. J Clin Oncol.2002; 20:1215-21.

11. Douglas OS, Garcia MJ, Haines DE, Lai WW, Manning WJ, Patel AR, et al. ACCF/ASE/AHA/ASNC/HFSA/HRS/SCAI/SCCM/ SCCT/ SCMR 2011 Appropriate Use Criteria for Echocardiography. J Am Soc Echocardiogr.2011;24:229-67.

12. Thavendiranathan P, GrantAD, Negishi T, Plana JC, Popovic' ZB, Marwick TH. Reproducibility of echocardiographic techniques for sequential assessment of left ventricular ejection fraction and volumes: application to patients undergoing cancer chemotherapy. J Am Coll Cardiol. 2013;61:77-84.

13. Paraskevaidis IA, Makavos G, Tsirigotis P, Psarogiannakopoulos P, Parissis J, Gkirkas K, et al. Deformation Analysis of Myocardial Layers Detects Early Cardiac Dysfunction after Chemotherapy in Bone Marrow Transplantation Patients: A Continuous and Additive Cardiotoxicity Process. J Am Soc Echocardiogr. 2017;30(11):1091-102.

14. Dorup I, Levitt G, Sullivan I, Sorensen K. Prospective longitudinal assessment of late anthracycline cardiotoxicity after childhood cancer: the role of diastolic function.2004. Heart. 2004;90(10):1214-6.

15. Pellicori P, Calicchia A, Lococo F, Cimino G, Torromeo C. Subclinical anthracycline cardiotoxicity in patients with acute promyelocytic leucemia in long-term remission after the AIDA protocol. Cong Heart Fail. 2012;18:217-21.

16. Serrano JM, Gonzalez I, Del Castillo S, Muniz J, Morales LJ, Moreno F, et al. Diastolic Dysfunction Following Anthracycline-Based Chemotherapy in Breast Cancer Patients: Incidence and Predictors. The Oncologist. 2015;20:864-72.

17. Stoodley PW, Richards DAB, Hui R, Boyd A, Harnett PR, Meikle SR, et al. Two-dimensional myocardial strain imaging detects changes in left ventricular systolic function immediately after anthracycline chemotherapy. Euro J Echocardiogr. 2011;12:945-52.

18. Barendswaard EC, Prpi H, Van der Wall EE, Camps JA, Keizer HJ, Pauwels EK. Right ventricule wall motion abnormalities in patients treated with chemotherapy. Clin Nucl Med.1991;16(7):513-6.

19. Lang RM, Badano LP, MD, Mor-Avi V, Afilalo J, Armstrong A, Ernande L, et al. Recommendations for cardiac chamber quantification by echocardiography in adults: an update from the American Society of Echocardiography and the European Association of Cardiovascular Imaging. J Am Soc Echocardiogr. $2015 ; 28: 1-39$.

20. Jenkins C, Moir S, Chan J, Rakhit D, Haluska B, and Marwick TH. Left ventricular volume measurement with echocardiography: a comparison of left ventricular opacification, three-dimensional echocardiography, or both with magnetic resonance imaging. Eur Heart J. 2009;30(1):98-106.

21. Muraru D, Badano LP, Piccoli G, Gianfagna P, Del Mestre L, Ermacora D, et al. Validation of a novel automated border-detection algorithm for rapid and accurate quantitation of left ventricular volumes based on three-dimensional echocardiography. Eur J Echocardiogr. 2010;11(4):359-68.

22. Dorosz JL, Lezotte DC, Weitzenkamp DA, Allen LA, Salcedo EE. Performance of 3-dimensional echocardiography in measuring left ventricular volumes and ejection fraction: a systematic review and meta-analysis. J Am Coll Cardiol. 2012;59(20):1799-808.

23. Walker J, Bhullar N, Fallah-Rad N, Lytwyn M, Golian M, Fang T, et al. Role of three-dimensional echocardiography in breast cancer: comparison with two-dimensional echocardiography, multiple-gated acquisition scans, and cardiac magnetic resonance imaging. J Clin Oncol. 2010;28(21):3429-36.

24. Hoffmann R, Bardeleben S, Cate F, Borges AC, Kasprzak J, Firschke C, et al. Assessment of systolic left ventricular function: a multi-centre comparison of cineventriculography, cardiac magnetic resonance imaging, unenhanced and contrast-enhanced echocardiography. Eur Heart J. 2005;26:607-16.

25. Farsalinos KE, Daraban AM, Unlu S, Thomas JD, Badano LP, Voigt JU. Headto-Head Comparison of Global Longitudinal Strain Measurements among Nine Different Vendors The EACVI/ASE Inter-Vendor Comparison Study. J Am Soc Echocardiogr. 2015;28:1171-81.

26. Stanton T, Leano R, Marwick TH. Prediction of All-Cause Mortality From Global Longitudinal Speckle Strain Comparison With Ejection Fraction and Wall Motion Scoring. Circ Cardiovasc Imaging. 2009;2:356-364.

27. Charbonnel C, Convers-Domart R, Rigaudeau S, Taksin AL, Baron N, Lambert J, et al. Assessment of global longitudinal strain at low-dose anthracycline-based chemotherapy, for the prediction of subsequent cardiotoxicity.Eur Heart J Cardiovasc Imaging 2017; 18:392-401.

28. Mousavi N, Tan TC, Ali M, Halpern EF, Wang L, Scherrer-Crosbie M. Echocardiographic parameters of left ventricular size and function as predictors of symptomatic heart failure in patients with a left ventricular ejection fraction of 50-59\% treated with anthracyclines. Eur Heart J Cardiovasc Imaging. 2015;16:977-84.

29. Kang Y, Xu X, Cheng L, Li L, Sun M, Chen H, et al. Two-dimensional speckle tracking echocardiography combined with high-sensitive cardiac troponin $\mathrm{T}$ in early detection and prediction of cardiotoxicity during epirubicine-based chemotherapy. Eur J Heart Fail. 2014;16:300-8.

30. Sawaia H, Sebag IA, Plana JC, Januzzi JL, Ky B, Cohen V, et al. Early detection and prediction of cardiotoxicity in chemotherapy-treated patients. Am J Cardiol. 2011;107(9):1375-80.

31. Sawaia H, Sebag IA, Plana JC, Januzzi JL, Ky B, Tan TC, et al. Assessment of echocardiography and biomarkers for the extended prediction of cardiotoxicity in patients treated with anthracyclines, taxanes and traztuzumab. Circ Cardiovasc Imaging. 2012;5(5):596-603.

32. Negishi K, Negishi T, Hare JL, Haluska BA, Plana JC, Marwick TH. Independent and Incremental Value of Deformation Indices for Prediction of TrastuzumabInduced Cardiotoxicity. J Am Soc Echocardiogr. 2013;26:493-8. 
33. Fallah-Rad N, Walker JR, Wassef A, Lytwyn M, Bohonis S, Fang T, et al. The utility of cardiac biomarkers, tissue velocity and strain imaging, and cardiac magnetic resonance imaging in predicting early left ventricular dysfunction in patients with human epidermal growth factor receptor ii-positive breast cancer treated with adjuvant trastuzumab therapy. J Am Coll Cardiol. 2011;57:2263-70

34. Aiken MJ, Suhag V, Garcia CA, Acio E, Moreau S, Priebat DA, et al. Doxorubicin-induced cardiac toxicity and cardiac rest gated blood poll imaging. Clin Nucl Med. 2009;34(11):762-7.

35. Schwartz RG, Jain D, Storozynsky E. Traditional and novel methods to assess and prevent chemotherapy-related cardiac dysfunction noninvasively. J Nucl Cardiol. 2013;20(3):443-64.

36. Corbett JR, Akinboboye OO, Bacharach SL, Borer JS, Botvinick EH, DePuey EG, et al. Equilibrium radionuclide angiocardiography. J Nucl Cardiol.2006;13(6):e56-e79.

37. Strashun AM, Goldsmith SJ, Horowitz SF. Gated blood pool scintigraphic monitoring of doxorubicin cardiomyopathy: comparison of camera and computerized probe results in 101 patients. J Am Coll Cardiol.1986;8(5):1082-7

38. Armenian SH, Lacchetti C, Barac A, Carver J, Constine LS, Denduluri N, et al. Prevention and Monitoring of Cardiac Dysfunction in Survivors of Adult Cancers: American Society of Clinical Oncology Clinical Practice Guideline. J Clin Oncol. 2016;35:893-911.

39. Fatima N, Zaman UM, Hashmi A, Kamal S, Hameed A. Assessing adriamycin-induced early cardiotoxicity by estimating left ventricular ejection fraction using technetium-99m multiple-gated acquisition scan and echocardiography. Nucl Med Commum.2011;32(5):381-5.

40. Tantawy AA, Elmasry AO, Shaaban M, Toaima DN, Shahat AM. Radionuclide ventriculography detects early anthracycline cardiotoxity in children with Hodgkin Lymphoma. J Pediatr Hematol Oncol.2011;33:e132-e137.

41. Pepe A, Pizzino F, Gargiulo P, Perrone-Filardi P, Cadeddu C, Mele D, et al. Cardiovascular imaging in the diagnosis and monitoring of cardiotoxicity: cardiovascular magnetic resonance and nuclear cardiology J Cardiovasc Med 2016, 17 (suppl 1):e45-e54

42. Debatin JF, Nadel SN, Paolini JF, Sostman HD, Coleman RE, Evans AJ, et al. Cardiac ejection fraction: phantom study comparing cine MR imaging, radionuclide blood pool imaging, and ventriculography. J Magn Reson Imaging.1992;2(2):135-42.

43. Moon JC, Lorenz CH, Francis JMm, Smith JC, Pennell DJ. Breath-hold FLASH and FISP cardiovascular MR imaging: left ventricular volume differences and reproducibility. Radiology.2002;223(3):789-97.

44. Drafts BC, Twomley KM, D'Agostino R Jr, Lawrence J, Avis N, Ellis LR, et al. Low to moderate dose anthracycline-based chemoterapy is associated with early noinvasive imaging evidence of subclinical cardiovascular disease. JACC Cardiovasc Imag. 2013;6(8):877-85

45. Armstrong GT, Plana JC, Zhang N, Srivastava D, Green DM, Ness KK, et al. Screening adult survivors of childhood cancer for cardiomyopathy: comparison of echocardiography and cardiac magnetic ressonance imaging. J Clin Oncol. 2012;30:2876-84

46. Hundley WG. MRI in detecting heart damage in patients with cance receiving chemotherapy. http://clinicaltrials.gov/show/NCT01719562. Accessed june 27, 2017.

47. Bollache E, Redheuil A, Clément-Guinaudeau S, Defrance C, Perdrix L, Ladouceur $\mathrm{M}$ et al. Automated left ventricular diastolic function evaluation from phase-contrast cardiovascular magnetic resonance and comparison with Doppler echocardiography. J Cardiovasc Magn Reson. 2010;12(1):63.

48. Paelinck BP, de Roos A, Bax JJ, Bosmans JM, van Der Geest RJ, Dhond $D$, et al. Feasibility of tissue magnetic resonance imaging a pilot study in comparison with tissue Doppler imaging and invasive measurement. J Am Coll Cardiol.2005;45(7);1109-16.

49. Friedman MA, Bozdech MJ, Billingham ME, Rider AK. Doxorubicin cardiotoxicity: Serial endomyocardilal biopsies and systolic time intervals. J Am Med Assoc. 1978;240(15):1603-6.

50. Unverferth DV, Fetters JK, Unverferth BJ, Leier CV, Magorien RD, Arn Ar, et al. Human myocardial histologic characteristics in congestive heart failure. Circulation.1983;68(6):1194-200

51. Souto ALM, Souto RM, Teixeira ICR, Nacif MS. Myocardial viability on cardiac magnetic ressonance. Arq Bras Cardiol.2017;108(5):458-69.

52. Nathan M, Liu CY, Pierre C, David B, Lima JAC. Assessment of myocardial fibrosis with cardiac magnetic resonance. J Am Coll Cardiol.2011;57(8):891-903.

53. Sibley CT, Noureldin RA, Gai N, Nacif MS, Liu S, Turkbey EB, et al. T1 Mapping in cardiomyopathy at cardiac MR: comparison with endomyocardial biopsy. Radiology.2012;265(3):724-32.

54. Jordan JH, Vasu S, Morgan TM, D'Agostino Jr RB, Meléndez GC, Hamilton CA, et al. Anthracycline-Associated T1 mapping characteristics are elevated independent of the presence of cardiovascular comorbidities in cancer survivors. Circ Cardiovasc Imaging.2016;9:e004325.

55. Lota AS, Gatehouse PD, Mohiaddin RH. T2 mapping and T2* imaging in heart failure. Heart Fail Rev.2017;22:431-40.

56. Thavendiranathan P, Amir E, Bedard P, Crean A, Paul N, Nguyen $\mathrm{ET}$, et al. Regional myocardial edema detected by T2 mapping is a feature of cardiotoxicity in breast cancer patients receiving sequential therapy with anthracyclines and trastuzumab. J Cardiovasc Magnet Res.2014;16(Suppl 1):P273.

57. Halliburton SS, Abbara S, Chen MY, Gentry R, Mahesh M. SCCT guidelines on radiation dose and dose-optimization strategies in cardiovascular CT. Cardiovasc Comput Tomogr.2011;5:198-224

58. Man SR, Man SB, Lal MJ. Role of cardiac CTA in estimating left ventricula volumes and ejection fraction. World J Radiol.2014;6(9):669-76.

59. Nacif MS, Kawel N, Lee JJ, Chen X, Yao J, Zavodni A, et al. Interstitia myocardial fibrosis assessed as extracellular volume fraction with lowradiation-dose cardiac CT. Radiology.2012;264(3):876-83 